\title{
The Gross Morphometry and Histology of the Male Accessory Sex Glands in the Greater Cane Rat (Thryonomys swinderianus, Temminck)
}

\author{
Adebayo, A.O. ${ }^{1,2}$, Oke, B.O. ${ }^{2}$ and Akinloye, A. $\mathrm{K}^{1}$ \\ ${ }^{1}$ Department of Veterinary Anatomy, University of Agriculture, Abeokuta. \\ ${ }^{2}$ Department of Veterinary Anatomy, University of Ibadan, Ibadan.
}

With 8 figures

Received November 2009, Accepted for publication December 2009

\begin{abstract}
In this study, the gross morpho-metry and histology of the vesicular, the prostate and the bulbourethral glands were investigated in ten male greater cane rats (Thryonomys swin-derianus Temminck) bred and raised in captivity at Igbesa, in Ogun state, Nigeria. The results showed that the cranial lobes of the vesicular glands were diver-gent with branches and the caudal lobes opened separately into the urethra. The ampulla of the ductus deferens was absent. Most of the secretory cells in the bulbourethral gland have round, basally located nuclei with prominent nucleoli and poorly stained cytoplasm. The gross and the histological features of the prostate gland were similar to that of the rabbit and the giant rat. The morphometry revealed that there was no significant correlation between the weights of the accessory glands and the testes (prostate $r^{2}=0.05$; vesicular $r^{2}=0.04$; bulbourethral $r^{2}=0.03 ; p<$ 0.05), whereas there was a positive correlation between the weights of the accessory glands and the age of the animals (prostate $r^{2}=0.61$; vesicular $r^{2}$ $=0.62 ;$ bulbourethral $r^{2}=0.54 ; p<$ 0.05). These findings showed that age was a factor in the full development of the accessory glands. This study
\end{abstract}

provides baseline data that could be used for further research on the accessory sex glands of the male cane rat.

\section{Key words}

Accessory, sex gland, Greater cane rats, Gross morphometry, Histology.

\section{Introduction}

The greater cane rat (Thryonomys swinderianus, Temminck) is a prolific wild rodent, of the order hystricomorpha that is currently found only in Afric (Adoun, 1993). It is vigorously hunted and exploited in most areas, particularly in West Africa south of the Sahara (Asibey, 1974; Ajayi and Tewe, 1980). Currently, it is undergoing domesticcation and captive rearing in this region and the recent trend in its farming is towards increase stock levels and intensification of production practices (Adu et al., 2005). Thus, a good understanding of the reproductive biology particu-larly of the anatomy of the male reproductive system is very vital (Segatelli, et al., 2004).

The accessory sex glands which include the prostate, vesicular, ampu- 
llae of vas deferens and bulbourethral glands play an important role in the reproductive process (Chughtai, et al., 2005). The morphology and histology of these glands vary widely among different mammalian species (Thomas and Marker, 2006). Within the rodents, a variety of combinations of accessory sex glands have also been described. While the cape porcupine possesses only a prostate gland and seminal vesicle but no coagulating gland (Van Aarde and Skinner, 1986), the rabbit (Holtz, 1972), the giant rat (Oke, 1988) as well as the cape mole rat (Bennett and Jarvis, 1988) and the pocket gopher (Vaughan, 1962) are known to possess a prostate, seminal vesicle, coagulating gland, Cowper's glands, and preputial glands. The blind mole rat have been reported to possess only the prostate and the coagulating gland, while Cuban Hutia, an hystricomorphic rodent has no prostate gland but an extra paired vesicular gland (Weir, 1974; Gottreich, et al., 2001).

This study describes the morphology and the histology of the accessory gland of the greater cane rat (Thryonomys swinderianus, Temminck). Following Kalra and Kalra (1979), who showed that growth and secretory activeties of the accessory sex glands in rats are entirely dependent on testosterone which is primarily derived from the testis, this work also examines the correlation between the testicular weight and the weights of the accessory sex glands as well as their variation with the age of the animals.

\section{Materials and Method}

\section{Animals:}

A total of eighteen (18) adult male greater cane rats, bred (with known dates of birth) and raised in captivity,

J. Vet. Anat. were used in the study. They aged between 13 and 41 months and weighed between $1.4 \mathrm{~kg}$ and $4.01 \mathrm{~kg}$ $(1400$ - 4010g). All the animals had brownish perineal staining which was taken as index of sexual maturity in male cane rats as reported by Adu and Yeboah (2003). They were maintained on Elephant grass stems and water was given ad libitum

\section{Sample collection}

Each animal was weighed alive and sacrificed after anaesthesia with chloroform in a closed container. The abdominal part was then dissected open through a mid ventral abdominal incision. The ischiatic arch was completely removed to expose the reproductive organs. The testis, the prostate, vesicular and bulbourethral glands were dissected out, collected and examined to evaluate the organs grossly. They were weighed (using the microwa analytical balance) and the volumes were estimated by water displacement method to determine the gross morphometry of the organs.

\section{Histological procedure}

Samples of the testes, seminal vesicles, prostate and bulbourethral glands were fixed in Bouin's fluid for 72 hours, dehydrated in graded alcohol cleared in two jars of xylene and embedded in paraffin wax. Sections of $5 \mu$ thick were stained with Haematoxylin and Eosin ( $H$ \& E). All the slides were examined under the Olympus BX 50 light microscope to evaluate the histological features.

\section{Statistical Analysis:}

The data were subjected to the correlation analysis to examine the relationship between and within the 
data using Microsoft Excel ${ }^{\circledR}$ data analysis tool.

\section{Results:}

Generally the greater cane rat was observed to posses the vesicular, prostate and the bulbourethral glands as shown in Figure 1and 2. However, the ampullae was absent in this animal.

\section{Morphology of the accessory glands Vesicular gland}

The vesicular gland in the greater cane rat was observed to be a paired transparent elongated tubes extending into the abdominal cavity and constituting the most cranial of the male accessory organs (Fig. 1 and 2). The pair was observed to be separated at the cranial portion, but converged caudally as they move towards the neck of the bladder. The cranial part possesses $4-8$ short branches, $0.5 \mathrm{~cm}$ in length with pointed extremities and extended more craniad than the urinary bladder even when the latter is fully distended and reached well into the abdominal cavity (Fig. 1 and 2). At the caudal part, the gland was unbranched and attaches to each other as they taper into ducts which open separately into the pelvic urethra. Also, close to the caudal end, the deferent ducts joined the ventral wall of the gland and open together into the pelvic urethra (Fig. 2). The size and storage capacity of the gland was observed to depend on the degree of distension with fluid secretion. The colourless secretions become viscous to gel-like or even solid when exposed to air.

Histologically, the wall of vesicular gland was observed to be thin and transparent having predominantly loose connective tissue with few bundles of smooth muscle fibres. The gland was divided into lobes by the connective tissue trabeculae which lie internal to the few smooth muscle layers. The lamina propria formed finger-like projections that extend into the lumen of the gland. The mucosa (epithelium and lamina propria) in each lobe was thrown into branching folds with frequently anastomosing secondary and tertiary folds all projecting into the lumen of the gland. The result is the formation of slit-like cavities and recesses, lined by glandular epithelium made up of low simple columnar cells in the mucosa. The gland which was a compound branched tubular to tubuloalveolar gland had the apical surface of the cells covered with a few short microvilli and the nuclei were round and basally located with prominent nucleolus (Fig. $3)$.

The height of the secretory epithetlium at the mucosa decreases craniocaudally, while the amount of the smooth muscle fibre in the wall increases caudally. The simple epithetlium was replaced by the transitional epithelium characteristic of the urinary excretory duct as the gland opened into the pelvic urethra.

\section{Prostate gland}

The prostate gland of the greater cane rat was observed to be a paired cauliflower-shaped gland that lied on both sides of the caudal part of vesicular gland. Each consists of both dorsal and ventral lobes which shared the same connective tissue covering (Fig.1 and 2). The dorsal group of the gland had darker brown colour compare to the ventral group and was made up of 4-6 lobes, with each having ducts that opened into the pelvic urethra. The ventral group was smaller with a light brown colour and fewer lobes than the dorsal group (Fig. 2). It was fixed in 
position by the fibrous connection between its connective tissues and the retroprostatic fascia as well as the passage of the urethra through it.

Histologically, the prostate was observed to be surrounded by connective tissue capsule that was interspersed with smooth muscle fibres. Trabeculae from the capsule divide the gland parenchyma into several compartments. Each of the compartments was lined with simple columnar cells of varying heights that are thrown into extensive branching folds which project into the lumen of the compartment (Fig. 4 ). The nuclei of secretory epithelium were round, basally located with prominent eccentrically located nucleolus (Fig. 5). The glandular epithelium that lines the excretory duct changed to transitional epithelium near the pelvic urethral opening.

\section{Bulbourethral gland}

The bulbourethral gland was observed to be the most caudal of the male accessory sexual gland in the greater cane rat. This paired gland was completely embedded in the bulbocavernosus muscle in the region of the crus of the penis. Each of the glands was a gourd- shaped structure that projected caudo-laterally from the point of its opening into the urethra (Fig. 1 and 2). It was yellowish in colour in the fresh state with a smooth shining surface. The gland had a single excretory duct that was relatively long and pierces the wall of the pelvic urethra at the crus of the penis where it opened.

Histologically, the gland was covered by a capsule of connective tissue with smooth and skeletal muscles. Trabeculae from the capsule divided the gland into lobules (Fig. 6). A section through the gland revealed tightly packed round to oval-shaped glandular alveoli which constituted the secretory unit and surrounded by thin connective tissue derived from the interlobular connective tissue. The secretory epithelium is simple columnar cells arranged round a small central lumen (Fig. 6). Although the nuclei of some of the cells show dorso-ventral compression, most of the cells have round basal nuclei with prominent nucleolus and poorly stained cytoplasm (Fig. 7).

\section{Morphometry of the accessory glands}

The mean volumes, weight and the relative weights of the accessory glands and testis were summarized in Table 1. While the coefficients of correlation $\left(r^{2}\right)$ between the testis and the accessory glands (Table 2) showed a low correlation, there was a positive correlation between the weights of the accessory glands and the age of the animals (prostate $r^{2}=0.61$; vesicular $r^{2}=0.62$; bulbourethral $\left.r^{2}=0.54 ; p<0.05\right)$ as shown in the scattered diagram (Fig. 8).

\section{Discussion}

The morphology and combinations of the accessory sex glands in the greater cane rat are different from that of subterranean Cuban Hutia (Capromys pilorides) but similar to that of other hystricomorphic rodents in possessing the prostate, vesicular and bulbourethral glands (Weir, 1974). The absence ampulla gland observed in the greater cane rat confirms the reports of Weir (1974) that hysricomorphic rodents only have vesicular gland, prostate gland and Cowper's glands. The ampulla has also been reported to be absent in the tomcat (Ellenport, 1975) and boar (Sisson, 1975). 
The structure of the vesicular gland in the cane rat is unique in that the branching observed on the cranial part of the gland has not been reported in any rodent. It however holds some similarity with that of the guinea pig as a long thin-walled cylindrical tube with smooth surfaces (Mann, 1964).

The low correlation between testicular weight and weights of the accessory glands is unexpected since the glands are known to respond to changing level of the male hormone, testosterone primarily produced in the testis. This perhaps, is connected with the timing of full development of the accessory glands in the greater cane rat. Marty et al. (2003) reported variation in the timing of full development of the accessory glands in humans, dogs, rats and mice. In rat, prostate and vesicular glands attain their full development by 28-35 days and 40-50 days postnatal respectively with parallel increase in testosterone levels. According to Sandberg et al. (1980), growth of the prostate, the only accessory sex gland, in adult dog appears to proceed at steady rate up to about 11 years of age and its histological appearance varies with age. Although the blood testosterone level was not determined in this study, the histology of this gland is the same at different ages. Therefore, the positive correlation observed between the weights of the glands and age showed the possibility of increasing growth with age. This finding lends credence to the fact that the timing of full development of the glands might be responsible for the low correlation observed between the weights of the glands and the testicular weight.

In conclusion, this study establishes the unique anatomy of the male accessory sex glands in the greater cane rat and proffer explanation for the unexpected low correlation between the weights of the accessory glands and the testis. These findings provide baseline information that could be used for further research on the male accessory sex glands in the greater cane rat.

\section{References:}

Adu, E. K, Otsyina, R.H and Agyei A. D (2005): The efficacy of different dose levels of albendazole for reducing fecal worm egg count in naturally infected captive grass cutter (Thryonomys swinderianus, Temminck). Livestock research and rural development. 17 (11) 1-6

Adu, E. K and Yeboah, S (2003): On the use of perineal stain as an index of sexual maturity and breeding condition in the male greater cane rat (Thryonomys swinderianus, Temminck). Tropical Animal Health and Production, 35(5), 433-439

Adoun C (1993) : Place de l'aulacode (Thryonomys swin-derianus) dans le regne animal et sa repartition geographique In: Schrage $R$ and Yewadan L.T. (editors) $1^{\text {ere }}$ Conference Internationale sur l'Aulacodi-culture: Acquis et perspectives, 35 40.

Ajayi, S.S and Tewe, O.O (1980): Food preferences and carcass composition of the Grasscutter (Thryonomys swinderianus) in captivity. African J. Ecology 18 (2 \& 3) $133-140$.

Asibey, E.O.A. (1974): Wildlife as source of protein in Africa: South of the Sahara. Biol Conserv 6(1): $32-39$.

Bennett, N., and Jarvis, J. U. M 
(1988): The reproductive biology of the Cape mole rat Georychus capensis (Rodentia, Bathyergidae). Journal of Zoology (London) 214:95-106.

Chughtai, B., Sawas, A., O'malley, R.

L., Naik, R. R., Ali Khan,S. and Pentyala, S (2005): A neglectted gland: a review of Cowper's gland. Inter-national Journal of Andrology. 28: $74-77$.

Ellenport, C. R (1975): Carnivore Urogenital system. In: Sisson and Grossman's, The anatomy of the domestic animals (Robert Getty, Ed.). Fifth ed. W.B. Saunders Co., Philadelphia, London and Toronto, Vol. II, page 1576.

Gottreich, A., Hammel, I., Yogev, L., Bartoov, B. and Terkel, J. (2001): Structure and function of accessory sex glands in the male blind mole rat (Spalax ehrenbergi). The Journal of Mammalogy 82(1):201-208.

Holtz, W.H (1972): Structure, function and secretions of reproductive organs in the male rabbit. Ph.D Thesis, Cornell University,U.S.A

Kalra, P. S. and Kalra. S. P (1979):

Regulation of gonadal steroid rhythms in rats. Journal of Steroid and Biochemistry 11:981-987.

Mann, T. (1964): Male accessory organs of reproduction, and their secretory product: the seminal plasma. Pp. 37-78: In The biochemistry of semen and of the male reproductive $\operatorname{tract}(T$. Mann, ed.). Meth-uen, London, United Kingdom

Marty, M.S., Chapin, R. E., Parks, L.G., Thorsrud, B. A (2003): Development and maturation of the male reproductive system. Birth defect research (Part B) 68: 125-136.
Oke, B.O. (1988): Some aspects of the reproductive biology of the male African giant rat (Cricetomys gambianus, Waterhouse). Ph.D. Thesis, University of Ibadan.

Sandberg A.A., Karr J.P., Muntzing J. (1980): The prostates of dog, baboon and rat. In: Spring-Mills E, Hafez ESE, editors. Male accessory sex glands. Biology and pathology, New York: Elsevier/North Holland Biomedical Press. Pp 565-608.

Segatelli, T. M., França, L. R., Pinheiro, P. F. F., Alemida, C. C. D., Martinez, M. and Martinez, F. E. (2004): Spermatogenic Cycle Length and Spermatogenic Efficiency in the Gerbil (Meriones unguiculatus). Journal of Andrology, Vol. 25, No. 6. Pp. $1-21$.

Sisson, S. (1975): Sisson and Grossman's The Anatomy of the Domestic Animals (Robert Getty, ed.). Fifth edition. W.B. Saunders Co., Philadelphia, London and Toronto, Vol. I, p. 531.

Thomson A. A. and Marker P. C.

(2006): Branching morphogenesis in the prostate gland and seminal vesicles. Differentiation, Vol. 74 Issue. $7, \mathrm{Pp}$ $382-392$.

Van Aarde, R. J., and Skinner. J. D.

(1986): Reproductive biology of the male Cape porcupine (Hystrix africae-australis). Journal of Reproduction \& Fertility 76:-545-552.

Vaughan, T. A. (1962): Reproduction in the plains pocket gopher in Colorado. Journal of Mammalogy 43:1-13. 
Weir, B. J (1974): Reproductive characteristics of hystricomorph rodents. Symposium in Zoology and Society London 34:265-301.

Table 1: The means and standard errors of the volumes, the weights and relative weights (weight/body weight) of the testis and male accessory sex gland in the greater cane rat (Thryonomys swinderianus, Temmincks).

\begin{tabular}{|l|c|c|c|}
\hline & Organ volume $(\mathrm{ml})$ & Organ weight $(\mathrm{g})$ & Relative weight $(\%)$ \\
\hline Body weight & - & $2200 \pm 60$ & 100 \\
\hline Testis & $1.250 \pm 0.45$ & $1.183 \pm 0.32$ & 0.0537 \\
\hline $\begin{array}{l}\text { Vesicular } \\
\text { gland }\end{array}$ & $1.040 \pm 0.34$ & $1.048 \pm 0.52$ & 0.0476 \\
\hline $\begin{array}{l}\text { Prostate } \\
\text { gland }\end{array}$ & $0.920 \pm 0.12$ & $0.904 \pm 0.33$ & 0.0411 \\
\hline $\begin{array}{l}\text { Bulbourethral } \\
\text { gland }\end{array}$ & $0.180 \pm 0.04$ & $0.148 \pm 0.058$ & 0.0067 \\
\hline
\end{tabular}

Note: In the case of paired organs, the mean of a pair is used in the generation of the mean and standard errors.

Table 2: The correlation coefficients between testicular weight and weights of the accessory sex glands in the greater cane rats (Thryonomys swinderianus, Temmincks).

\begin{tabular}{|l|c|c|c|c|}
\hline & Testis & $\begin{array}{c}\text { Prostate } \\
\text { gland }\end{array}$ & $\begin{array}{c}\text { Bulbourethral } \\
\text { gland }\end{array}$ & $\begin{array}{c}\text { Vesicular } \\
\text { gland }\end{array}$ \\
\hline Testis & 1.00 & & & \\
\hline Prostate gland & 0.05 & 1.00 & & \\
\hline Bulbourethral gland & -0.03 & 0.68 & 1.00 & \\
\hline Vesicular gland & 0.04 & 0.97 & 0.51 & 1.00 \\
\hline
\end{tabular}

Note: In the case of paired organs, the mean of a pair is used in the generation of the coefficients of correlation. 




Figure 1: Photograph of ventral view the male accessory sex glands in the greater cane rat. Observe the relationship of the sex glands to one another.



Figure 2: The schematic diagram of the ventral view of the male accessory sex glands in the greater cane rat. Note the branching of the cranial part of the vesicular glands. All the glands including the bladder open separately into the pelvic urethra. 


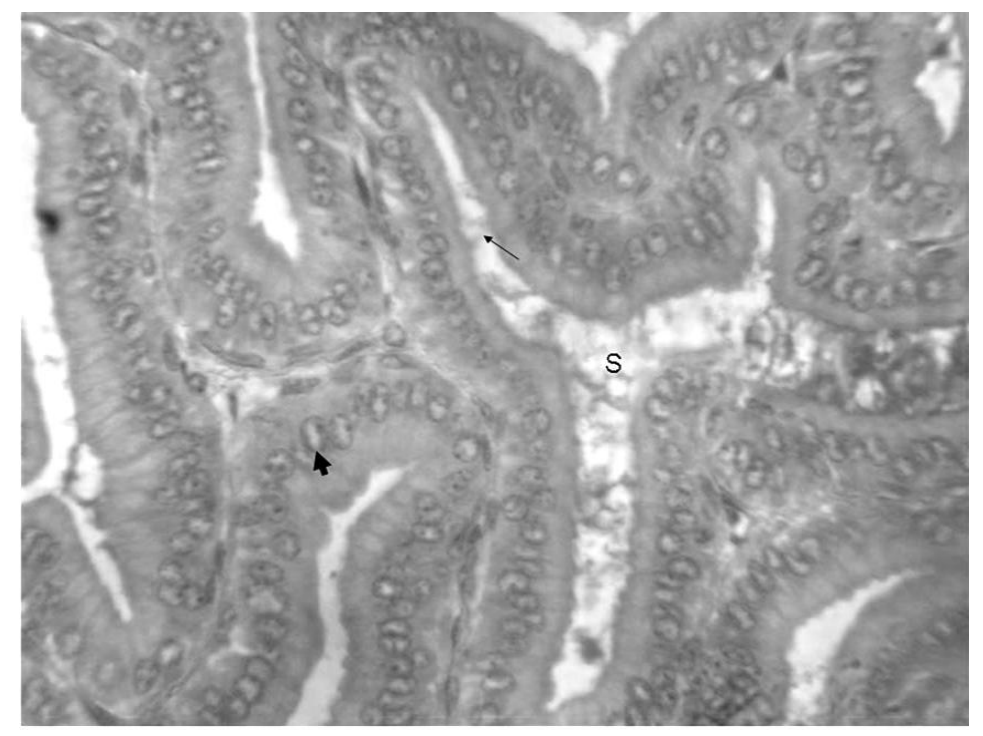

Figure 3: The glandular epithelium of vesicular gland. Observe the simple columnal cells with basally located nuclei and prominent nucleolus (arrow head), the gel-like secretions (S) from the cells as well as the microvilli (arrow). H\&E x 1000.

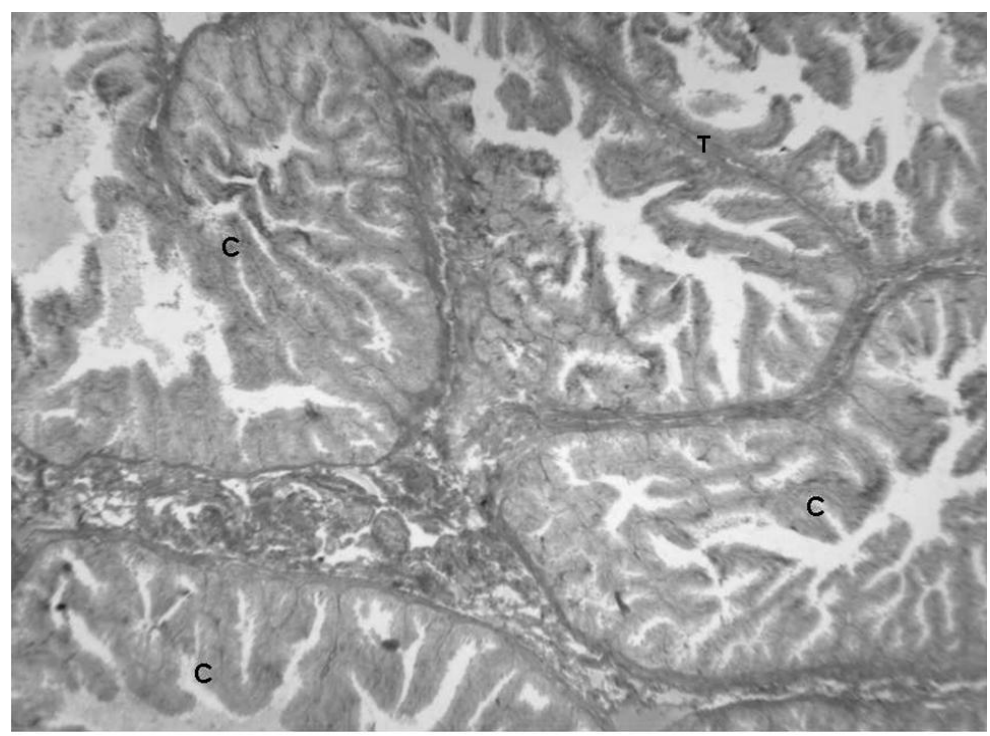

Figure 4: Section of the prostate gland of the greater cane rat. Note the compartment (C) separated by trabeculae (T). H\&E x 100. 


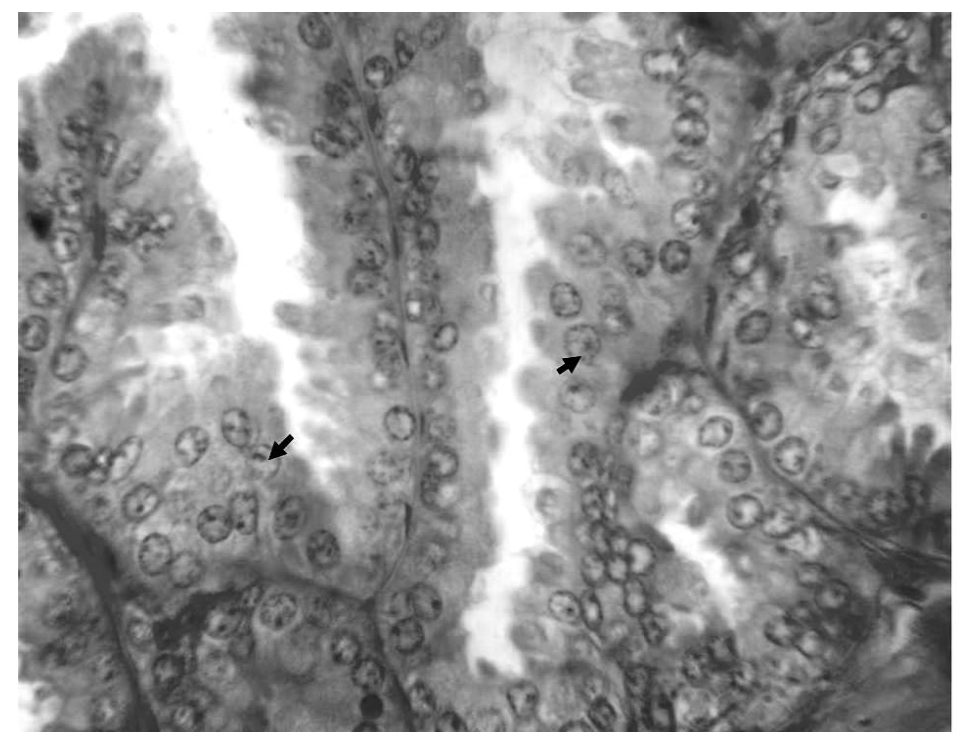

Figure 5: The secretory epithelium of the prostate gland in greater cane rat. Note the branching of the epithelium, the simple columnal cells with basally located round nuclei as well as the prominent eccentrically located nucleolus (arrows). H\&E x 1000.

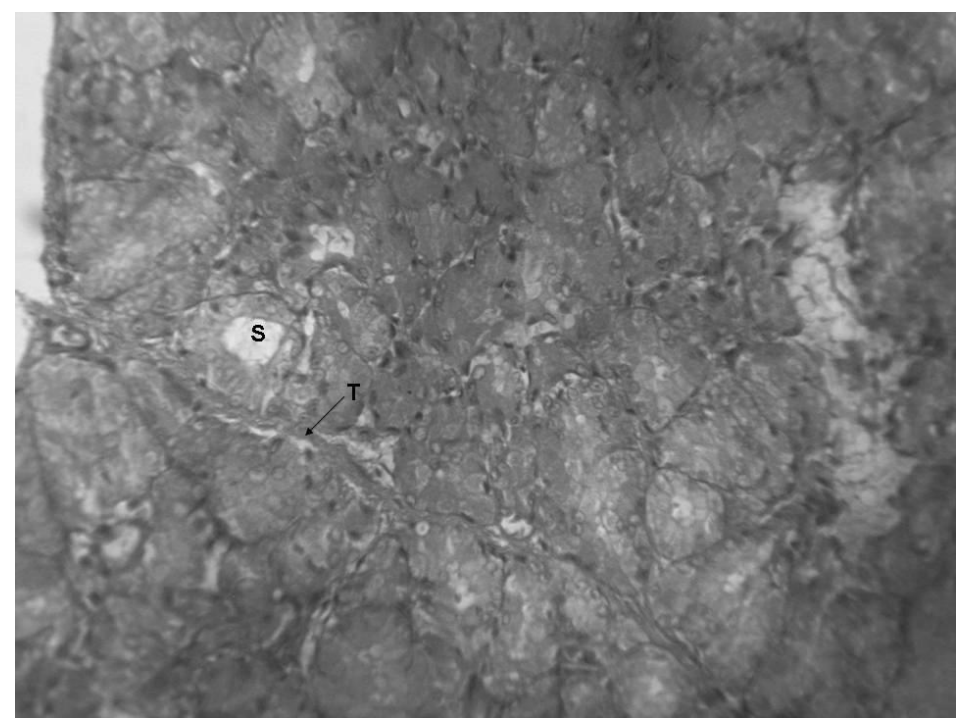

Figure 6: Photomicrograph of the bulbourethral gland of the greater cane rat. Observe the secretory unit of the gland $(\mathrm{S})$ and the trabecula $(\mathrm{T})$ dividing the gland parenchyma into lobules. H \&E x 400 . 




Figure 7: The secretory unit (S) of bulbourethral gland in the greater cane rat which comprises simple columnar cells that surround a small central lumen. Note the compressed nucleus of some of the secretory cells (white arrow) and the predominantly round nuclei with prominent nucleolus (black arrow) in most of the cells. H\&E x1000

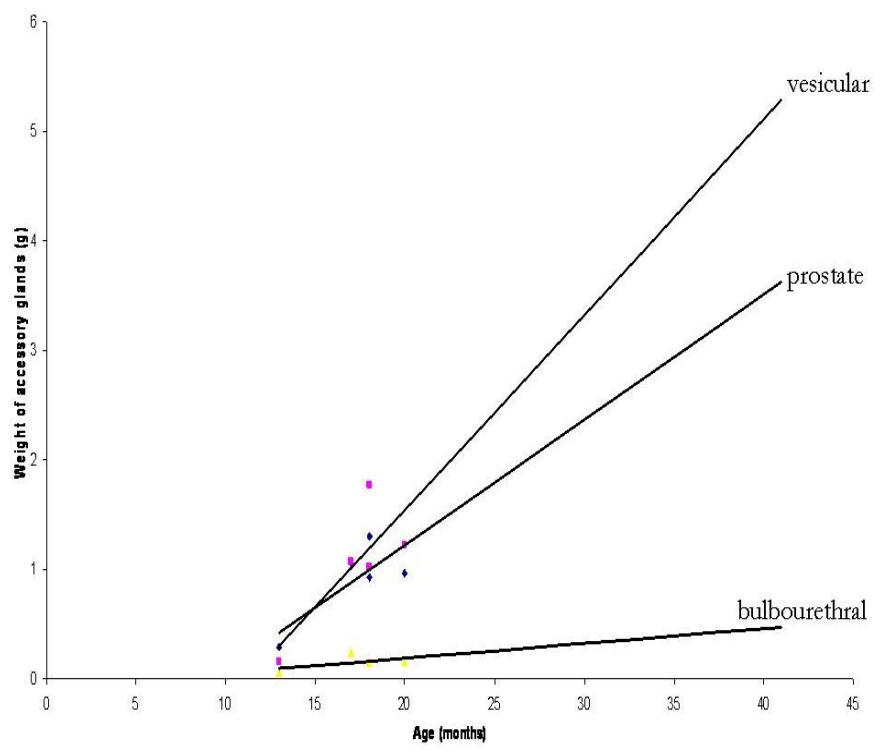

Figure 8: The scattered diagram illustrating the positive linear relationship between the three accessory sex glands and age in sexually matured male greater cane rat (Thryonomys swinderianus Temmincks). 